Faculdade de Ciências Econômicas UFRGS

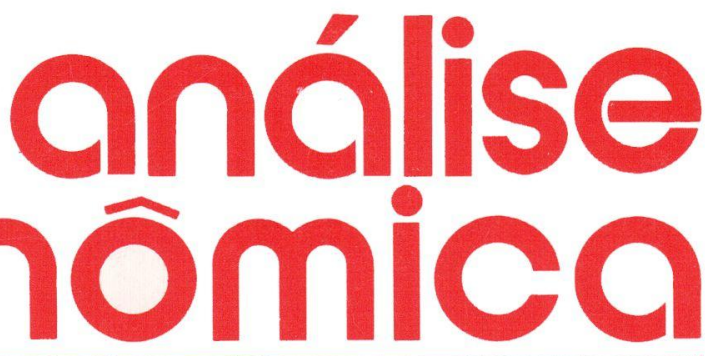

- MONETARY OVERHANG AND REFORMS IN THE 1940

Radḱger Dornbusch

Holger Wolf

- ALTA INFLAČ̃o E ESTABLLIZAÇÃo: GRADUALISMO OU TRATAMENTO DE CHOQUE

Fernando J. Cardim de Carvalho

- A ABORDA GEM MICROECONOMICA DA INDEXACAO SALARIAL

Gícomo Belbinotto Nete

- "OS NEO-RICARDIANOS" DE FRANK HAHN

Roberto Camps Mormes

- OS NEO-RICARDIANOS

Frank Hahn

- INCDENCIA TRIBUTÁRIA E OS GASTOS EM ALIMENTOS

Joso Rogerio Samson

- CONSID praÇÓES SOBRE A REFORMA TRIBUTARIA

Raymundo Guimarîtes

- eFErTgs espaciais da aUtomaÇáo BANCARIA

Moema Castro Debiagl

Otilin Beatris Kroefi Carrion

- DESENYOLVIMINTO ECONOMICO E A QUESTAO AME IENTAL

Ademar Ribelro Romeliro

- CONSIDERACóES SOBRE A DISGERTAÇAO DE MESTI ADO Nali de Jesus de Sorra
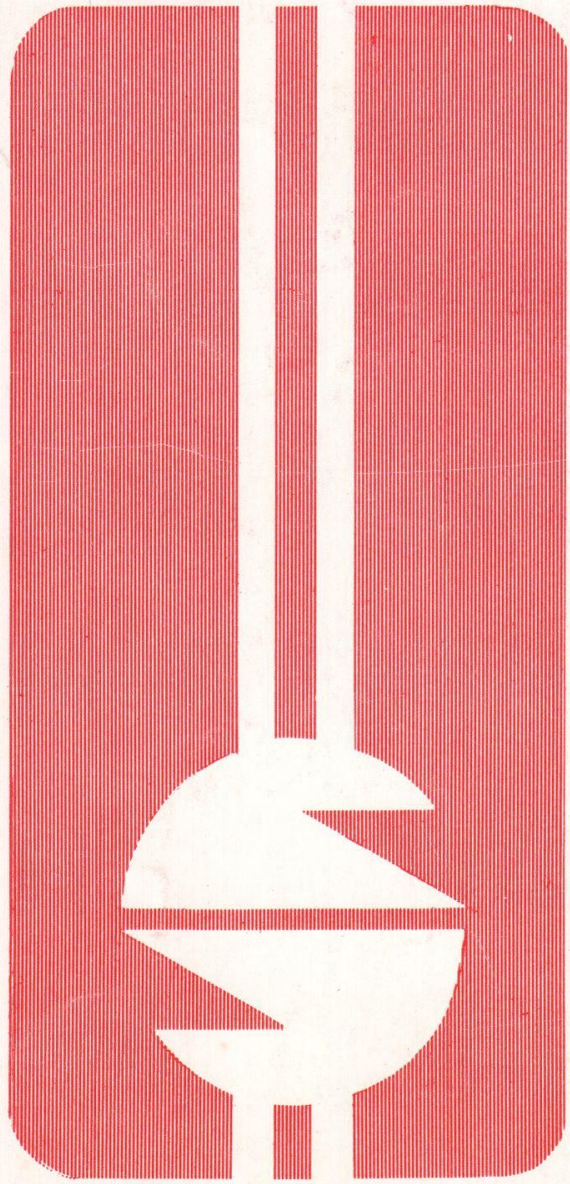
UNIVERSIDADE FEDERAL DO RIO GRANDE DO SUL

Reitor: Prof Tuiskon Dick

FACULDADE DE CIÊNCIAS ECONÔMICAS

Diretora: Prof ${ }^{a}$ Yeda Rorato Crusius

CENTRO DE ESTUDOS E PESQUISAS ECONÔMICAS

Diretor: Reinaldo Ignacio Adams

DEPARTAMENTO DE CIÉNCIAS ECONÔMICAS

Chefe: Prof. Pedro Cezar Dutra Fonseca

CURSO DE PÓS-GRADUAÇÃO EM ECONÔMIA

Coordenador. Prof. Nali de Jesus de Souza

CURSO DE PÓS-GRADUAÇÃO EM ECONOMIA RURAL

Coordenador: Prof. Atos Freitas Grawunder

CONSELHO EDITORIAL: Achyles Barcelos da Costa, Aray Miguel Feldens, Atos Freitas Grawunder, Carlos Augusto Crusius, Ernani Hickmann, João Rogério Sanson, Juvir Luiz Mattuella, Maria Imilda da Costa e Silva, Nali de Jesus de Souza, Nuno Renan Lopes de Figueiredo Pinto, Otilia Beatriz Kroeff Camion, Otto Guilherme Konzen, Paulo Alexandre Spohr, Pedro Cezar Dutra Fonseca, Reinaldo Ignacıo Adams, Roberto Camps Moraes, Valter José Stülp, Yeda Rorato Crusius, David Garlow (Wharton Econometrics Forecasts Association, E.U.A.), Edgar Auguisto Lanzer (UFSC), Eleutério F. S. Prado (USP), Fernando Holanda Barbosa (FGV/RJ), Gustavo Franco (PUC/RJ), Joaquim Pinto de Andrade (UNB), Juan H. Moldau (USP), Werner Baer (Univ. de lllinois, E.U.A.)

COMISSĀO EDITORIAL: Atos Freitas Grawunder, Pedro Cezar Dutra Fonseca, Reinaldo Ignacio Adams e Roberto Camps Moraes.

EDITOR: Nali de Jesus de Souza

SECRETARIA: Maria Ivone de Mello (normalização), Vanete Ricacheski (revisão de textos), Zélide Bregalda (Secretária)

FUNDADOR: Prof. Antôniı Carlos Santos Rosa

Os materiais publicados na revista Análise Econômica são de exclusiva responsabilidade dos autores. É permitida a reprodução total ou parcial dos trabalhos, desde que seja citada a fonte.

Aceita-se permuta com revista congêneres. Aceitam-se, também, livros para divulgaçäo, elaboração de resenhas ou recensōes.

Toda correspondência, material para publicação (vide normas na $3^{\text {a }}$ capa), assinaturas e permutas devem ser dirigidos ao seguinte destinatário:

\section{PROF. NALI DE JESUS DE SOUZA \\ Revista Análise Econômica \\ Av. João Pessoa, 52 \\ 90.040 - PORTO ALEGRE (RS), BRASIL}

Telefones: (0512) 28.1633; 24.6022 - Ramais 3440 e 3507

FAX: (0512) 25.1067 


\title{
DESENVOLVIMENTO ECONÔMICO E A QUESTÃO AMBIENTAL: ALGUMAS CONSIDERAÇÕES 1
}

\author{
Adernar Ribeiro Romeiro2
}

\section{SINOPSE}

Neste ensaio exploratório descrevemos em linhas gerais o debate sobre lesenvolvimento econôrnico no pós-guerra, ressaltando a idţia subjacente de que o crescimento económico era condiç̧̌o necessária e suficiente. A questhó ambiental, além obviamente da realidade dramática da maioria dos palses subdesenvolvidos depois de um longo perfodo de crescimento econ 6 mico,

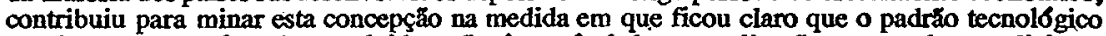
dominante nos pafses desenvolvidos năo é passivel de generalizaçăo em escala mundial por razóses de ordem ecológica. Neste sentido, a superaçăo do subdesenvolvimento requer um processo de crescimento económico qualitativamente distinto. Săo discutidas quais seriam as pre-condiçoes para que isto ocorra.

\section{INTRODUÇĀG}

Neste ensaio exploratório é retraçado sucintamente, em primeiro lugar, o debate sobre desenvolvimento econômico no pós-guerra, destacando-se a idéia subjacente de que, a longo prazo, o crescimento econômico é condição necessária e suficiente para a superação do subdesenvolvimento. A questão ambiental, reduzida à sua dimensão de base de recursos naturais, tende a ser vista como um eventual obstáculo ao crescimento, mas un obstáculo pouco importante. Em segundo lugar, a experiência japonesa, em oposição à brasileira, \& citada como exemplo bem-sucedido de desenvolvimerito equilibrado. Um dos elementos chave do sucesso japonês é visto na permanência de relações comunitárias tradicionais (de caráter feudal), cuja regra de ouro era a garantia de emprego. Este fato representou o predomínio de uma racionalidade macrossocial sobre a racionalidade microeconômica ao nfvel de cada unidade

1 Texto apresentado no Seminário sabre Meio Ambiente e Desenvolvimento Sustentável organizado pelo IPEA/SEMAM, Brasflia, Novembro de 1990.

2 Professor do Departamento de Economia da UFF.

\begin{tabular}{|l|l|l|l|l|}
\hline ANÁLISE ECONÔMICA & ANO 9 & № 16 & SETEMBRO, 1991 & P.141-152 \\
\hline
\end{tabular}


produtiva. O resultado mais notável desta característica da sociedade japonesa foi um processo de modernização da agricultura cujo padräo tecnológico foi compatível com as especificidades de recursos humanos e naturais do pars. Como conseqüência, o êxodo rural se deu de forma equilibrada, de acordo com a expansão das oportunidades de emprego no setor urbano industrial.

Finalmente, se discute o papel do agravamento dos problemas ambientais, juntamente com o fracasso do esforço desenvolvimentista, no abandono da idéia de que o crescimento econômico é condição necessária e suficiente para a melhoria da qualidade de vida da população, na medida em que tornou-se claro que o padrão tecnológico dominante nos países desenvolvidos não $\varepsilon$ passível de generalização em escala mundial por razões de ordem ecológica. Neste sentido, a superação do subdesenvolvimento requer um processo de crescimento econômico qualitativamente distinto, onde a racionalidade microeconômica de agentes privados é submetida a uma racionalidade macrossocial que garante a existência não somente de uma solidaridade sincrônica entre as classes sociais (justiça social), como tambem de uma solidaridade diacrônica entre as geraçōes (preservação do patrimônio natural).

\section{O DEBATE SOBRE DESENVOLVIMENTO ECONÔMICO}

No perfodo que se abre com o firn da II Guerra Mundial, perifodo de excepcional prosperidade, a expectativa inicial era de grande otimismo no que concerne às possibilidades de superação do atraso econômico. No debate sobre o desenvolvimento, a perspectiva dominante $\varepsilon$ a de que o crescimento econômico por si só é condição necessária e suficiente para o desenvolvimento econômico, entendido este último como algo mais amplo, envolvendo o bem-estar social, qualidade de vida, etc. Schumpeter (1976) dizia que com 50 anos de crescimento econômico à taxa anual de $2 \%$ (descontado o aumento da população) não haveria país no mundo que não eliminasse a pobreza. O problema dos chamados países subdesenvolvidos se resumia, portanto, em alcançar as pre-condiçōes para o crescimento sustentável.

Rostow (1960), cujo trabalho foi extremamente influente na Epoca, procura descrever quais seriam estas prế-condiçōes para se atingir o estágio em que ocorre a "decolagem" rumo ao crescimento sustentado. Esta descrição é análoga àquela feita por Marx dos fatores que levaram à eclosão da revolução industrial capitalista. $O$ momento da decolagem, por sua vez, tem origem a partir de um forte e determinado estímulo que tanto pode ser uma revolução política, a introdução de uma grande inovação ou impactos externos (por exemplo, o colapso do setor exportador induzindo a substitivição de importações). $O$ essencial não é a forma do 
estŕmulo, mas o fato de que o desenvolvimento anterior da sociedade permite uma resposta positiva, sustentada e auto-reforçada ao estímulo. A taxa de investimento se eleva fortemente, as técnicas produtivas se transformam, a renda per capita cresce levando a uma diversificação da demanda que, por sua vez, fecha o circuito ampliando novamente as oportunidades de investimento.

A partir desta perspectiva teórica, a solução para o problema do subdesenvolvimento passa pela identificação dos fatores que bloqueiam a emergência das pré-condiçōes para a decolagem. Entre os principais obstáculos ao crescimento podem ser alinhados: a baixa produtividade decorrente de fatores naturais e humanos; o excesso demográfico; o cfrculo vicioso da pobreza; a deterioração dos termos de intercâmbio; e, finalmente, as imperfeições do mercado.

No que concerne a baixa produtividade, a importância dos fatores naturais $\epsilon$ considerada pequena, seja em termos de área agrícola ou de recursos minerais disponfveis. O Japão é citads freqüentemente, bem como a Suíça e outros países europeus, como exemple de país que não tem base importante de recursos naturais, mas que conseguiu atingir a etapa da decolagem. A questão ambiental, reduzida assim à sua dimensão de base de recursos naturais, tende a ser vista, portanto, como um eventual obstáculo ao crescimento, mas um obstáculo pouco importante. O fator chave é a qualificaçāo dos recursos humanos. É necessário elevar o nível de educação, queimando etapas, se possível, através da importação de técnicos, tanto da área de educação propriamente dita (professores), como profissionais especializados. Autores como Baran observam (com razão) que o investimento em educação por ser de longa maturação não interessa cos homens de negócios destes pafses, habituados que estão a lucros fáceis e indiferentes à sorte da população a quem encaram apenas como uma reserva de mão-de-obra barata.

A demografia excessiva, poi sua :ez, representa um. obstáculo ao crescimento na medida em que o esforço do investimento em infra-estrutura, ar inclufdo a infra-estrutura educacional, $\varepsilon$ proporcional ao aumento da população. O montante de investimento necessário $\ell$ estimado em cerca de $4 \%$ da renda nacional para cada $1 \%$ de crescimento demográfico. O terceiro cbstáculo é representado pelo círculo vicioso da baixa renda per capita, baixa taxa de poupança, baixa acumulação de capital e novamente, baixa renda per capita. Autores neoclássicos como Viner (1969) e Meier (1969) recomendam a ruptura deste círculo através de medidas de estímulo a poupança, da seleção cuidadosa das prioridades de investimento e do recurso a empréstimos externos, desde que em condiçōes favoráveis e que não se concentrem em enclaves exportadores. A estes argumentos, autores marxistas como Baran (1969) opõem argumentos de ordem sócio-polf́tica para mostrar sua impossibilidade. 
Por exemplo, a taxa de poupança é baixa porque as elites que concentram a renda são perdulárias; além disso, consomem produtos importados estreitando ainda mais o mercado interno. Vêm se somar ainda a estas baixas oportunidades de investimento as incertezas provocadas pelo medo de uma revolta social.

O obstáculo, representado pela deterioraçāo dos termos de intercâmbio, foi a grande bandeira levantada pela CEPAL em favor da industrialização, como a única safda para o crescimento econômico, contra as teses das vantagens comparativas que justificavam a divisão internacional do trabalho vigente. A tese da deterioração dos termos de intercâmbio era basicamente uma questão emṕrica. Baseou-se inicialmente numa serie de índices anuais para o Reino Unido onde parecia claro uma tendência de perda relativa dos preços dos produtos primários vis-a-vis aos dos produtos industrializados. As causas desta deterioração decorriam da baixa elasticidade da demanda por produtos primários, por parte das economias industrializadas confrontada com a inelasticidade da oferta destes por parte das economias primário-exportadoras.

No que concerne aos produtos alimentares, a baixa elasticidade da demanda resultava da chamada lei de Engel, isto $\varepsilon$, da tendência de redução relativa do consumo destes produtos, à medida em que a renda aumenta; quanto às materias-primas de origern agrfcola, a redução relativa da demanda decorria de sua substituiçăo crescente por produtos sintéticos. Do lado da oferta, a tendência era de aumento constante da produção em função principalmente da oferta ilimitada de mão-de-obra nos paŕses periféricos; a existência de um excedente estrutural de trabalho mantinha os salários constantes ao nível de subsistência, concentrado os frutos do progresso técnico nas, mãos da classe capitalista que tendia a reinvesti-los na produção de produtos primários.

Acrescente-se a isto, o fato de que a estrutura prcdutiva nos países desenvolvidos era altamente oligopolizada e os sindicatos organizados e poderosos, o que impedia a tránsferência dos frutos do progresso técnico para os preços dos produtos. Estas proposiçōes da CEPAL deram origem a um grande debate cuja tônica era demonstrar empiricamente a validade de seus pressupostos. De qualquer modo, a tese da deterioração dos termos de troca contribuili decisivamente para abalar a convicção existente de que a especialização de cada paŕs, segundo as vantagens comparativas, era condição suficiente para o desenvolvimento econômico. Ficava claro que a "especialização" dos países centrais na produção industrial decorria simplesmente do fato destes terem se industrialirado antes.

Finalmente, o obstáculo representado pelas imperfeições do mercado tem relevância especial no caso de paśses como o Brasil, onde o processo de industrialização havia consideravelmente avançado sem, no entanto, eliminar as principais caracteristicas que marcam o subdesen- 
volvimento. As imperfeições do mercado decorriam do que Kindlerberger batizou de "desequilibrio estrutural ao nivel dos fatores de produção". Furtado3, no Brasil, desenvolve amplamente esta tese. Este desequilibrio estrutural se devia à importação de tecnologias "labor-saving" incorporadas em máquinas e equipamentos provenientes de parses onde a disponibilidade relativa de fatores de produção era distinta. Nestes, o trabalho havia se tornado um fator relativamente escasso, de modo que a transposição da tecnologia aí gerada para economias onde o trabalho era um fator abundante provocava um desequilíbrio estrutural ao nível dos fatores, elevando a relação capital-produto em meio à escassez de capital.

Desse modo, se torna impossivel para estas economias absorver o setor de subsistência apesar das altas taxas de retorno obtidas. A solução para o problema do desemprego estrutural estaria, portanto, na internalização do setor produtor de bens de capital, de modo a permitir a concepção de máquinas e equipamentos adequados à disponibilidade relativa de fatores da economia.

\section{RACIONALIDADE MICROECONÔMICA VERSUS RACIONALIDADE MACROSSOCIAL}

As principais correntes teóricas em liça neste debate, estruturalista, neoclássica e marxista, embora por razões distintas, entendem que o setor agrícola nos países subdesenvolvidos não tem nenhum papel a cumprir como fonte de emprego neste momento de arrancada para o crescimento sustentável. Para os estruturalistas, a hipótese de excedente estrutural de mão-de-obra no campo (desemprego disfarçado) lhes voltava toda a atenção sobre as possibilidades de tornar o setor urbano-industrial capaz de absorver completamenie o que era considerado como o setor de subsistência.

Para os autores neoclássicos, não havia excedente estrutural no campo, de modo que o êxodo rural implicava forçosamente a modernização da agricultura; a evidência gritante de um excedente de trabalho no setor urbano-industrial cu e simplesmente negada ou admitida até certo ponto como resuitado de distorções provocadas pelo Governo nos preços relativos dos fatores de produção. Tanto estruturalistas como neoclássicos ignoram o papel do bloqueio institucional do acesso à terra como a fonte principal do excedente "estrutural de mão-de-obra". Para os marxistas, ao contrário, este bloqueio do acesso à terra faz parte da logica capitalista cie expropriação dos produtores diretos de modo a transformálos em trabalhadores sem outra coisa para vender que sua força de tra-

3 Para uma análise mais ampla da pasiçăo de Furtado ver Romeiro, A.R. (1981). 
balho e em permanente excesso frente a demanda por trabalho (exército de reserva).

O êxodo rural, perverso ou não segundo as várias correntes, era visto como sinal de desenvolvimento econômico. Em nenhum momento se procurou refletir seriamente, à luz da própria experiência dos parses capitalistas avançados, sobre o papel fundamental cumprido pelo setor agrícola como regulador da oferta da mão-de-obra para o setor urbanoindustrial em expansão. E, no entanto, não se pode compreender o processo de crescimento econômico com distribuição de renda observado nestes paŕses sem analisar este papel cumprido pelo setor agrícola.

O caso do Japão é certamente o mais ilustrativo entre todos. Na segunda metade do século XIX, a partir da era Meiji (1862), o Japão procura acelarar o processo de industrialização e modernização acuado como estava pelo poderio tecnológico e militar do Ocidente em expansão. A absorção dos conhecimentos científicos e tecnológicos ocidentais era condição indispensável e esta poderia ser feita de duas maneiras diferentes: a) incorporados em máquinas e equipamentos importados; b) atraves da criação de instituições de pesquisa capazes de absorver os prinćpios científicos e tecnológicos fundamentais. A preponderância de uma ou outra forma implicava a dependência ou independência tecnoeconómica de uma nação e, no caso do Japão, também polftica, ser ou não submetida ao jugo colonial.

O processo de modernização e desenvolvimento econômico passava em primeiro lugar pelo vasto setor agrícola que ocupava a maior parte da população economicamente ativa. No que concerne a este setor, o ocidente oferecia na época dois estilos diferentes de modernização: o europeu, direcionado principalmente para o aumento do rendimento da terra e o americano, centrado no aumento da produtividade do trabalho atraves da mecanizā̄ão extensiva das operações agricolas. Alem disso, havia uma inovação instituciónal da maior importância: as estações experimentais agrícolas. Esta inovação institucional surge na Alemanha em meados do século XIX e se difunde rapidamente pelo continente europeu. O modelo alemão de pesnuisa agrícola foi rapidamente absorvido. Também se importou inicialmente máquinas e equipamentos agrícolas americanos. No entanto, estava claro que a utilização destes teria um impacto devastador na estrutura produtiva da agricultura japonesa baseada em pequenas unidades de produção. $O$ resultado teria sido algo próximo àquele que se observou no Brasil e outros paises latino-americanos: a expulsão em massa de camponeses em direção a um setor urbano-industrial que não oferece ainda suficientes oportunidades de emprego, moradias, infra-estrutura urbana em geral. Desse modo, a importação pura e simples do modeio americano de mecanização agrícola foi rejeita- 
do em benefício dō desenvolvimento interno de máquinas e equipamentos agricolas adaptados à especificidade da estrutura produtiva japonesa.

O desenvolvimento agrícola do Japão foi um exemplo extremamente significativo de preponderância de uma racionalidade social mais geral sobre uma eventual racionalidade microeconômica ao nfvel de cada unidade produtiva. Eventual porque para as elites rurais japonesas mesmo que pudesse ser lucrativo expulsar os trabalhadores e mecanizar extensivamente suas lavouras, isto estava fora de cogitação, pois um laço de solidariedade comunitária tradicional as unia às populações camponesas. Neste aspecto, a iıerança feudal foi mantida. Uma das caracterfsticas mais marcantes do sistema feudal, comparado com o sistema capitalista, diz respeito justamente ao vínculo pessoal que une as classes dominantes e dominadas numa relação de compromisso que implica direitos e deveres reclprocos e que dispöe sobre a posse e uso dos recursos fundiários existentes.

A regra de ouro destas relações comunitárias tradicionais no Japão era a garantia de emprego. Assim, confrontadas com a necessidade de modernizar sua agricultura, as elites japonesas irão fazê-lo, mas de modo a preservar o nfvel de emprego. Havia consciência também de que a manutenção do nfvel de emprego não poderia ser obtida ao custo de uma redução da produtividade do trabalho agrícola. $O$ setor urbano-industrial em expansão necessitava quantidades crescentes de matérias-primas agricolas e alimentos. Assim, o aumento do emprego no setor agricola deveria ser acompanhado de um aumento da produtividade do trabalho.

O que é notável na sociedade agrícola japonesa é que, apesar do avanço da economia de mercado, o espúrito destas relações comunitárias tradicionais permaneceu em operação e gerou a força dinâmica decisiva de um processo de modernização agrícola vigoroso, mas equilibrado no que diz respeito a manutenção do nível de emprego. Isto evitou um êxodo rural descontrolado e a conseqüente degradação das condições de vida da população. Graças à permanência destas relaçốes comunitárias tradicionais, o Japão foi capaz de absorver ciência e tecnologia agrícola importada do ocidente e adequá-las às suas especificidades naturais e à sua disponibilidade de recursos humanos. Assim, podemos dizer que, no Japão, o êxodo rural foi perfeitamente equilibrado; como nos Estados Unidos, embora por razões diferentes, os fatores de atração para as cidades também preponderaram sobre os fatores de expulsão do campo4.

O caso do Brasil é o oposto do Japonês, no sentido da predominância dos interesses dos grupos privados em detrimento daqueles da Nação como um todo. As elites brasileiras, tradicionalmente piratas e irrespońsáveis, em nenhum momento da história do País olharam para a

4 Uma excelente análise do papel do cetor agricola no processo de desenvolvimento econ反ీmioo do Japăo pode sef encontrada em Ishikawa, S. (1981). 
população em geral como parte de uma nação em formação. A aceleração do êxodo rural, a partir de meados da década de 60 , deveu-se fundamentalmente à expulsão dos trabalhadores residentes, seguida de um processo de mecanização extensivo, num contexto histórico de bloqueio sistemático do acesso às terras ociosas existentes. A este fluxo de trabalhadores sem terra vieram se juntar pequenos proprietários arruinados por uma política agricola viesada em função dos interesses dos grandes proprietários e pela especulação fundiária.

Ao contrário do caso do Japão e de outros parses capitalistas desenvolvidos, no Brasil os fatores de expulsão do campo foram mais importantes do que os fatores de atração das cidades; assim, o ritmo do êxodo rural foi largamente superior ao ritmo de expansão das oportunidades de emprego no setor urbano-industrial. Como agravante deste quadro, mas sendo-lhe perfeitamente coerente como outra face que $\epsilon$ da mesma moeda de indiferença das elites pelo povo, está o baixíssimo nivel de investimento em educação fundamental. Portanto, nâo há como se surpreender com o nfvel de concentração de renda observado depois de 40 anos de crescimento econômico acelerado, a taxas somente iguaiadas pelas apresentadas pelo Japão.

\section{MEIO AMBIENTE E DESENVOLVIMENTO ECONÔMICO}

O caso do Brasil é efetivamente paradigmático como exemplo de crescimento econômico excludente, fenômeno este que ficou patente nos anos oitenta na maioria dos chamados parses do Terceiro Mundo. A questão ambiental que adquire novo (e ao que parece, definitivo) fôlego apos o acidente nuclear de Chernobil, juntamente com a crise do "welfare state" nos países desenvolvidos, vêm se somar a este quadro sombrio apresentado pelos parses subdesenvolvidos como indutores da emergência de uma clara consciência mundial sobre dois fatos: a) 0 crescimento econômico ‘ condiçãó necessária mas não suficiente para a melhoria da qualidade de vida da população; b) o padrão tecnolégico dominante nos paŕses desenvolvidos não é passivel de generalização em escala mundial por razōes de ordem ecológica.

Por ocasião da primeira conferência mundial sobre a questão ambiental (Conferência de Estocolmo em 1972), esta consciência não era muito clara; dominava ainda a idéia de uma certa contradição entre preservação ambiental e crescimento econômico (este entendido como condição necessária e suficiente da elevação da qualidade de vida). $O$ exemplo de algumas economias agrárias, especialmente no Sahel africano, onde a degradação ambiental (dessertificação acelerada devido a práticas agropecuárias predatórias) se tornou um obstáculo decisivo ao desenvolvimento econômico, veio reforçar tambem esta conscientização 
sobre a necessidade e possibilidade de compatibilizar crescimento econômico com preservação ambiental. A isto vem se somar, nos parses industrializados, os problemas ambientais como aqueles provocados pelas chuvas ácidas, pelos resf́duos químicos, etc., bem como a ameaça representada pelo "efeito estufa".

No entanto, o velho confronto entre possibilistas culturais e deterministas geográficos ainda continua sob novas formas a propósito da profundidade das mudanças requeridas no atual padrão tecnológico e de consumo para compatibilizar crescimento econômico com preservação do meio. $\mathrm{Na}$ década de 70 , os primeiros eram claramente representados pelo "staff" de Hermann Khan do Hudson Institute (e, no campo sovietico, pelos planejadores das grandes obras como a reversão do curso dos rios siberianos) e os segundos pelos membros do chamado "Clube de Roma". Atualmente este conflito é menos marcado, mas permanece e decorre fundamentalmente de uma falsa percepção do que é natural (e equilibrado do ponto de vista ecológico) e do que $\varepsilon$ artificial (e desequilibrado ecologicamente).

E preciso ter claro que um ecossistema pode ser inteiramente artificial, isto é, construfdo pelo homem, e nem por isso ser desequilibrado dơ ponto de vista ecológico. Um exemplo disto é a agricultura camponesa européia tradicional. A partir de uma manipulação inteligente das complementaridades e simbioses existentes na natureza, esta agricultura foi capaz de aumentar fortemente a produção de alimentos e matérias-primas agrícolas sem romper com os equilfbrios ecologicos fundamentais. $O$ impasse ainda existente entre aqueles que têm uma fé ilimitada no progresso técnico de resolver os problemas ambientais sem mudar o atual padrão tecnológico e de consumo e aqueles que, ao contrário, não vêem safda senão através do crescimento zero e de uma regressão dos padrões de consumo atuais, pode e deve ser rompido.

Uma tertativa de romper este impasse já havia surgido por ocasião da Conferência Mundial de Estocolmo em 1972. Trata-se do que foi batizado dic Ecodesenvolvimentol. Por este conceito se entende um processo de crescimento que concilie viabilidade econômica, desejabilidade social e prudência ecológica. A viabilidade econômica pressupõe a concep̧̧ão de sistemas produtivos onde os custos de produção, medidos pela produtividade do trabalho obtida, sejam compatíveis com os niveis de bem-estar social considerados como minimamente aceitáveis. A desejabilidade social pressupóe a solidariedade sincr6nica entre classes sociais, o que implica optar por padrões tecnológicos que, guardada a primeira condição, propiciem uma distribuição mais equitativa da renda gerada.

$1 \mathrm{Um}$ dos principais teóricos desta linha de abordagem \& Ignacy Sachs, fundador e ex-diretor do Centro Internacional de Pesquisa sobre Desenvolvimento e Meio Ambiente, da Escola de Altos Estudos em Ciencias Sociais de Paris. 
Finalmente, a prudência ecológica é uma exigência da necessária solidariedade diacrônica entre gerações, implicando o uso parcimonioso dos recursos naturais não renováveis e sistemas de produção onde as grandes leis da natureza são respeitadas de modo a não transformar recursos renováveis em não renováveis.

$O$ processo de modernização da agricultura japonesa é um exemplo que atende perfeitamente as duas primeiras e parcialmente a última das condições do ecodesenvolvimento. $O$ caso do Brasil $\varepsilon$ o inverso. $O$ que $\varepsilon$ importante reter da experiência japonesa é a preponderância de uma racionalidade macrossocial sobre a racionalidade microeconômica de agentes privados. Isto $\epsilon$ fundamental para mudar o atual padrão de produção e consumo que se torna progressivamente inviável do ponto de vista ecológico nos parses industriais e que, por esta mesma razão, não é passível de generalização para o restante dos parses do globo.

No que concerne as alternativas tecnológicas ecologicamente equilibradas, a situação varia bastarte dependendo do setor produtivo. De modo geral, para o sctor industrial, o que existe disponivel não tecnologias de redução de poluição (filtros, sistemas de tratamento de efluentes, etc.); a concepção de sistemas produtivos a circuito fechado, isto $\epsilon$, onde os resfdufos de um determinado processo serve de matéria-prima a outro, ainda se encontra numa fase experimental. A agricultura, ao contrário, oferece um exemplo setorial bastante ilustrativo do que deve e pode ser feito e sob que condições. $O$ setor agrícola é o único setor produtivo que dispõe de uma alternativa tecnologica deste tipo já conhecida há bastante tempo.

A regra básica desta alternativa tecnológica é a manipulação inteligente das complementaridades e simbioses existentes na natureza. Tratase, na verdade, da recuperação da racionalidade da agricultura camponesa tradicional sob um outro nível de conhecimentos cientffico e tecnológico. A aplicação desta tecnologia exigiria do atual agricultor a recuperação da antiga capacidade perdida de gerir a diversidade contra a tendência observada de especialização extrema (monocultura). A agricultura ideal, do ponto de vista ecológico, é aquela baseada em rotações de culturas agronomicamente balanceadas, associadas à criação animal.

Os obstáculos a uma mudança deste tipo são grandes. Em primeiro lugar, estão os interesses das elites agrícolas via de regra especializadas na produção das culturas mais rentáveis. Esta é a lógica da monocultura: produzir apenas o produto que se apresenta mais rentável em cada momento. Em segundo lugar, estão os interesses dos diversos segmentos da agroindústria que trabalham com agricultores (geralmente pequenos) integrados ou semi-integrados, que produzem apenas o produto que lhes interessa. A política agricola governamental tende obviamente a beneficiar estes grupos de interesse. 
As possibilidades de mudança, no entanto, existem. Uma mudança na orientação atual da polf́tica agrícola (chegando até a obrigar os agricultores a internalizar os custos ecológicos da produção), na direção desejada encontra respaldo em dois elementos novos que vêm adquirindo um peso crescente: do lado da produção, o custo crescente das práticas convencionais; do lado do consumo, o aumento da consciência ecológica da população. Do lado da produção, o aumento dos custos de produção das práticas agrícolas convencionais se deve ao aumento do preço de um insumo fundamental deste padrão tecnológico que é o petróleo e ao crescente impacto da degradação do ecossistema agrícola sobre a produtividade. Solos degradados e polurdos têm menor capacidade de retenção de água e de nutrição vegetal; as culturas se tornam mais suscetfveis ao ataque de pragas e mais sensf́veis às variações climáticas. Do lado do consumo se nota uma crescente mobilização da população em favor de uma alimentação mais saudável; os níveis de tolerância legal de resfduos de pesticidas nos alimentos tendem a se reduzir.

Concluindo, do ponto de vista tecnológico já existe uma série de alternativas, mas cuja factibilidaơ'-depende, além da solução de problemas tecno-científicos, da superação de interesses privados através da internalização dos custos ecologicos. Neste sentido, o instrumental de cálculo destes custos já existente é extremamente útil; é preciso ter claro, no entanto, que sua aplicação $e$ antes de mais nada uma questão de poder. Poder que somente uma sociedade consciente e organizada pode ter. Além disto, é necessário ter em conta também que parte importante dos impactos ambientais são de caráter irreversível. Assim, a sociedade precisa se antecipar aos problemas, o que torna imprescindfvel dispor de uma estratégia de ação definida a partir do que se deseja e do que, nas condiçōes atuais de desenvolvimento cientffico e tecnológico, $€$ possível esperar.

\section{BIBLIOGRAFIA}

BARAN, P.A. A Ecuiomia Polftica do Subdesenvolvimento. In: AGARWALA, A, N. \& SINGH, S.P. (org.). A Economia do Subdesenvolvimento. Rio de Janeiro. Forense, 1969.

EHRLICH, P.A. Population, Ressources, Environnement: Issues in Human Ecoiugy. San Francisco. W.H. Freeman, 1970.

GOUROU, P. Pour une GEographie Humaine. Paris. Flammarion, 1972.

ISHIKA WA, S. Essays on Technology, Employment and Institutions in Economic Development: Comparative Asian Experience. Tokyo. Kinokuniya Company Ltd, 1981.

MEADOWS, D. et. al. Halte à la Croìssance. Paris. Fayard, 1972.

MEIER, G.M. O Problema do Desenvolvimento Econ6́mico Limitado. In: A Economia do Subdesenvolvimento. AGARWALA, A.N. \& SINGH, S.P. (org.). Rio de Janeiro, Forense, 1969.

RAPPORT DAG HAMMARSKJOLD, Que Faire. Das Hammarskjold Foundation, Uppsala, 1975. 
ROMEIRO, A.R. Os Fundamentos Teóricos do Estruturalismo: uma Análise da Contribuição de Celso Furtado. Campinas. UNICAMP, 1981. Dissertaçăo (mestr., econ.). Agriculture et Progrès Technique: une étude sur la Dynamique des Innovations. Paris. Ecole des Hautes Etudes en Sciences Sociales, 1986. These (dout, econ.). Alternative Developments in Brazil. In: GLAESER, B. The Green Revolution Revisited. Critique and Alternatives. London. George Allen and Unwin, 1987.

ROSTOW, W.W. The Stages of Economic Growth. Cambridge. Cambridge University Press, 1960.

SACHS, I. Stratégies de l'Écodéveloppment. Paris. Ed. Économie et Humanisme et les Ed. Ouvrieres, 1980.

- Développer les Champs de Planification. Paris. Universite Cooperative Internationale, 1984. (Cahiers de l'U.C.I., n.2).

SCHULTZ, T.W. Transforming Traditional Agriculture. New Haven. Yale University Press, 1964.

SCHUMPETER, J.A. Capitalism, Socialism and Democracy. London. George Allen and Unwin, 1976.

VINER, J.A. A Economia do Desenvolvimento. In: AGARWALA, A.N. \& SINGH, S.P. (org.). A Economia do Subdesenvolvimento. Rio de Janeiro. Forense, 1969.

\section{ABSTRACT \\ ECONOMIC DEVELOPMENT AND THE ENVIRONMENT PROBLEM: SOME CONSIUERATIONS}

This paper sumarizes the post-war debate on economic development, emphasizing the current idea that economic growth was the necessary and sufficient condition for it. Environmental issues, besides the dramatic situation of the majority of underdeveloped countries after a long period of fast economic growth, has contributed to undermine this idea; it became clear that the tochnological and consumption patterns of developed countries could not spread at all of the world by ecological reasons. In this sense, to overcome underdevelopement it is necessary a qualitatively different economic growth. The pre-conditions for that are discussed. 